\title{
Guidelines for Stress Management
}

\author{
Rita Karmakar* \\ Department of psychology, Amity University, India
}

Submission: April 06, 2017; Published: April 17, 2017

*Corresponding author: Rita Karmakar, Department of psychology, Amity University Kolkata, India, Tel: 9836171830;

Email: rk_r80@rediffmail.com

\section{Introduction}

Stress is omnipresent in every day's life of a person. According to Selye [1], stress is the nonspecific response of the body to any demand made upon it. Stress may be detrimental to physical and psychological health if it is prolonged and severe. But stress is not always bad. Eustress (good stress) influences positively by making life rewarding, challenging and energizing. Distress (bad stress) affects individuals negatively if not managed effectively. of late, researchers have argued that Challenge stressors (stressors associated with workload, deadlines and time urgency etc.) are different from Hindrance stressors (stressor that act as obstacles in reaching goals such as office policies, red tape, role ambiguity etc.). Research evidence suggests that challenge stressors produce less strain than hindrance stressors.

\section{Stress and Performance Relationship}

One of the most noticeable effects of stress in one's life is the changes in his performance. The relationship between stress and performance is better explained with the help of the following graph created by Nixon [2] which is based on the Yerkes Dodson Law [3] (Figure 1).

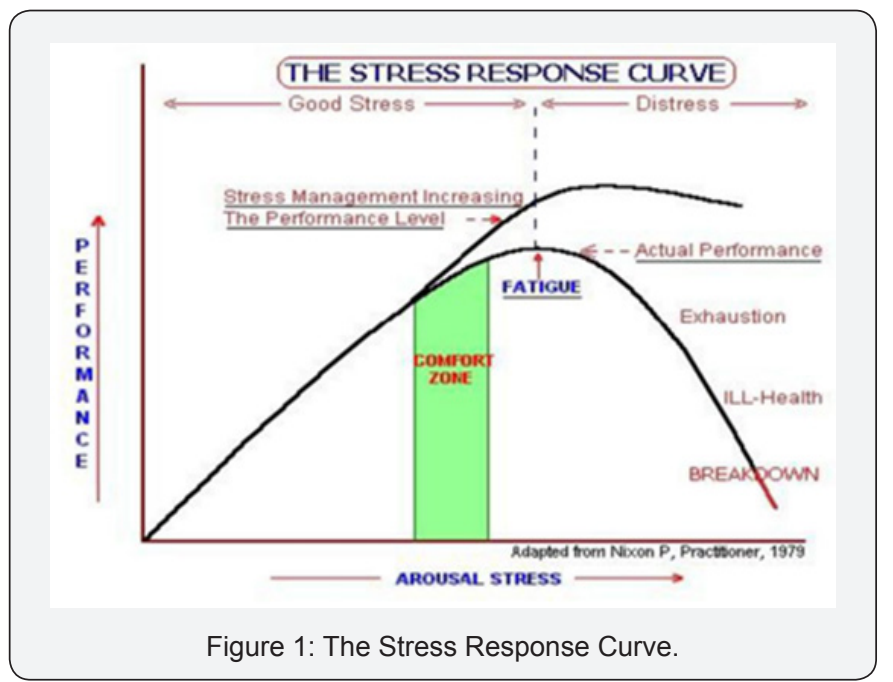

The above curve shows that the level of stress facilitates performance level to the point of eustress or good stress or healthy tension. The area called the Comfort Zone indicates the range of stress levels that we can absolutely manage and facilitates performance levels. As stress begins to be perceived as excessive, the person reaches a fatigue point wherein the performance levels starts to decline. The ultimate end of excessive level of stress is known as distress which leads to exhaustion and thereby burnout.

\section{Potential Factors of Stress}

\section{Environmental factors: Environmental factors include} the following
a. Economic uncertainty (contractual job)
b. Political uncertainty (political change) and
c. Technological change (technological innovation).

\section{Organizational factors: These factors include the following}

a. Task demands (task variety, working conditions and working hours)

b. Role demands (role ambiguity, role overload and role conflict) and

c. Interpersonal relationship (lack of social support from colleagues, sexual harassment, bullying etc.)

Personal factors: Some of the personal factors are as follows:

a. Family problems (marital problems, breaking of an intimate relationship, death of nearest and dearest one's in the family)

b. Economic problems

c. Personality (Type A personality, workaholism, perfectionism) 


\section{Typical Symptoms}

Symptoms of stress may be categorized as follows:

\section{Physiological Symptoms:}

a. Gain or loss of significant amounts of weight

b. Disorganized speech

c. Increase or decrease in appetite

d. Physical complaints without a medical cause, such as headache, stomach pains, etc.

e. Chronic fatigue

f. Constipation

g. Diarrhea

h. Neck cramps

i. Excessive sweating and

j. Increased heart rate and blood pressure

\section{Behavioural Symptoms:}

a. Frequent violent outbursts

b. Inattentiveness or Inability to focus on a specific topic in a conversation or activity

c. Excessive alcohol or drug use

d. Social isolation, withdrawal, lethargy

e. Expression of feelings of persecution, strong mistrust of others

f. Frequent class absence or disappearance over extended periods

g. Abrupt change in manner, style, or personal hygiene

h. Change in the sleeping habit

i. Self injury or suicidal tendency

j. Unusual ritualistic or repetitive behaviour (in extreme case Obsessive Compulsive Disorder or OCD)
k. Lack of assertiveness
l. Increased turnover
m. Increased absenteeism and
n. Burnout

\section{Psychological symptoms}
a. Experiencing psychological exhaustion
b. Depression
c. Anxiety
d. Dissatisfaction with interpersonal relationship
e. Restlessness and

f. Irritability

g. Procrastination

h. Boredom and

i. Expression of irrational fears (in extreme case phobia)

\section{Combating Against Stress}

Individual Approaches: An employee may take the responsibility for reducing his/her own stress level

a. Effective time management strategy: Making to do list, prioritizing activities by importance, scheduling activities according to priorities and learning to say "No" etc.

b. Stick to a healthy diet: Healthy diet helps to maintain healthy body and thereby minimizing the level of stress.

c. Physical exercise: Aerobics, jogging, swimming etc.

d. Relaxation techniques: Meditation, biofeedback, yoga etc.

\section{Organizational Approaches: Organizational strategies to reduce the level of stress among employees}

a. SMART goal setting: Helping employees to set SMART (Specific, Measurable, Attainable, Realistic and Time bound) goals.

b. Flexi-time: Allowing workers to start or end the workday earlier or later as per their convenience. It may reduce the stress of commuting in rush hour traffic and mostly applicable for working parents especially working mothers.

c. Work from home (WFH): Working from home provides employees more control over how they do their work and helps employees to better manage work-life balance.

d. Redesigning jobs: Giving more responsibility, meaningful job and autonomy to employees.

e. Increasing employee involvement in decision-making.

f. Creating support group: It may include colleagues at work, managers and other members at work. Individual in stress gets an opportunity to share his/her stressful experiences with other members of support group and thereby reducing the level of stress.

g. Wellness programs: Organizing workshop on stress management, conflict management, quit smoking and alcohol, regular exercise programs etc.

h. Introducing a Gamified Workplace to the employees: Gamified workplaces can be defined as organizations that use gamification principles to transform some of their work processes into a game-like experience for the employees. The long-term goal of a gamified workplace is to increase wellbeing at the organizational level (i.e., productivity) and personal level (i.e., work satisfaction). 
i. Music Therapy: Music is successfully used as a technique of stress reduction. Music is often successfully used in combination with other stress reduction techniques.

j. EAPs (Employee Assistance Programs): EAPs include health insurance plan, compensation claims and counseling benefits.

k. Healthcare advocacy: Offering personalized healthcare benefits, such as helping to resolve medical bills and interacting with insurance agents may help employees to reduce worry and stay focused on their job.

Stress can make an individual productive and constructive when it is well managed. The effect of stress is detrimental when it is beyond control. Positive attitude and relaxation therapy will be helpful to deal with stress effectively. Stress can be minimized if companies take the right steps. Stress-free employees perform better, work harder, feel happier and have a long term commitment to the organization. Having broader perspective of life will definitely change the perception of stress. Let us hope that we will be successful in making distress into eustress for our healthy lifestyle as well as organizational well being.

\section{Stress Counselors}

\section{Role of a counselor to overcome the level of stress}

When the problems faced by employees are severe, consultation with a trained person is needed. It's always a good idea to consult with counselors, who might be able to give feedback and suggestions for overcoming the stress level.

a. Active listening: The first, crucial step is listening to what the client has to say. Active listening allows the general practitioner to clarify the nature of the patient's concerns, and may allow patients to see more clearly the nature of their problems and devise their own strategies for dealing with problems.

After having clear idea about the problem, the counsellor decides the mode of treatment. Common treatments are as follows

a. Progressive muscular relaxation is a key element in stress management.

b. Biofeedback involves the measurement of physiological responses (for example, by electromyograph and galvanic skin response) and immediate feedback to the individual. The aim is to enhance awareness of the physiological changes that may accompany stress, so that the individual can develop greater control over these changes via techniques such as muscle relaxation

c. Cognitive restructuring includes thought reframing. It encourages the person to logically think through the stressful event.

d. Relaxation and meditation techniques to reduce stress levels.

\section{References}

1. Selye H (1979) The stress of my life: A scientist's memoirs. Van Nostrand, New York, USA.

2. Nixon P (1979) Stress Response Curve.

3. Yerkes RM, Dodson JD (1908) The relation of strength of stimulus to rapidity of habit-formation. Journal of Comparative Neurology and Psychology 18: 459-482.

\section{Your next submission with JuniperPublishers will reach you the below assets}

This work is licensed under Creative

DOI: 10.19080/PBSIJ.2017.03.555607
- Quality Editorial service

- Swift Peer Review

- Reprints availability

- E-prints Service

- Manuscript Podcast for convenient understanding

- Global attainment for your research

- Manuscript accessibility in different formats

( Pdf, E-pub, Full Text, Audio)

- Unceasing customer service

Track the below URL for one-step submission https://juniperpublishers.com/online-submission.php 